\title{
The contribution of water contact behavior to the high Schistosoma mansoni Infection rates observed in the Senegal River Basin
}

\author{
Seydou Sow ${ }^{1,2,3}$, Sake J de Vlas ${ }^{2}$, Foekje Stelma ${ }^{4}$, Kim Vereecken ${ }^{1}$, Bruno Gryseels ${ }^{1}$ and Katja Polman ${ }^{1 *}$
}

\begin{abstract}
Background: Schistosomiasis is one of the major parasitic diseases in the world in terms of people infected and those at risk. Infection occurs through contact with water contaminated with larval forms of the parasite, which are released by freshwater snails and then penetrate the skin of people. Schistosomiasis infection and human water contact are thus essentially linked, and more knowledge about their relationship will help us to develop appropriate control measures. So far, only few studies have related water contact patterns to infection levels.

Methods: We have conducted detailed direct water contact observations in a village in Northern Senegal during the first years of a massive Schistosoma mansoni outbreak to determine the role of human water contact in the extent of the epidemic.

We quantified water contact activities in terms of frequency and duration, and described how these vary with age and sex. Moreover, we assessed the relationship between water contact- and infection intensity patterns to further elucidate the contribution of exposure to the transmission of schistosomiasis.

Results: This resulted in over 120,000 recorded water contacts for 1651 subjects over 175 observation days. Bathing was the main activity, followed by household activities. Frequency and duration of water contact depended on age and sex rather than season. Water contacts peaked in adolescents, women spent almost twice as much time in the water as men, and water contacts were more intense in the afternoon than in the morning, with sex-specific intensity peaks. The average number of water contacts per person per day in this population was 0.42 ; the average time spent in the water per person per day was 4.3 minutes.
\end{abstract}

Conclusions: The observed patterns of water contact behavior are not unusual and have been described before in various other settings in sub-Saharan Africa. Moreover, water contact levels were not exceptionally high and thus cannot explain the extremely high S. mansoni infection intensities as observed in Northern Senegal. Comparison with fecal egg counts in the respective age and sex groups further revealed that water contact levels did not unambiguously correspond with infection levels, indicating that factors other than exposure also play a role in determining intensity of infection.

\section{Background}

In the late 1980s, Northern Senegal was confronted with a severe outbreak of Schistosoma mansoni infection after the construction of a dam on the Senegal River and subsequent water resource development. In a few years, the prevalence in Ndombo, the epicenter of the epidemic, rose from $0 \%$ (non existing) before 1988 to $75-100 \%$ in

\footnotetext{
* Correspondence: kpolman@itg.be

${ }^{1}$ Prince Leopold Institute of Tropical Medicine, Antwerp, Belgium

Full list of author information is available at the end of the article
}

1992, with the highest intensities of infection ever described world-wide $[1,2]$. These were attributed to intense transmission and the supposed lack of acquired immunity in this recently exposed community. Epidemiological studies in four successive cohorts, however, showed that infection intensities had similar age-related patterns as in conventional endemic situations in subSaharan Africa, i.e. with egg counts and antigen levels increasing to a peak in adolescents and strongly declining in adults $[1,3]$. This would leave age-related exposure differences as the most obvious explanation for the

\section{() Biomed Central}

(c) 2011 Sow et al; licensee BioMed Central Ltd. This is an Open Access article distributed under the terms of the Creative Commons Attribution License (http://creativecommons.org/licenses/by/2.0), which permits unrestricted use, distribution, and reproduction in any medium, provided the original work is properly cited. 
observed patterns. As the available water contact data at that time did not support this possibility, alternative explanations of age-specific mechanisms other than acquired immunity or exposure were put forward, such as skin permeability or hormonal factors $[2,4,5]$. Nevertheless, important questions on the role of exposure remain to be answered. It is still unclear if and to what extent the observed extremely high infection levels in Northern Senegal were due to intense exposure, and in how far the endemic-like age-related infection patterns were due to differences in exposure levels, measured by human water contact patterns as a proxy for true exposure.

Many studies have attempted to measure individuals' exposure, either by directly observing behavior at water sources [6-18], or indirectly by interview/questionnaire [19-27]. Only few studies attempted to quantify variables that are important in determining age and sex patterns of exposure from the corresponding patterns of water contact $[12,16,28-31]$ and even less tried to relate these to infection levels and patterns $[5,11,32,33]$.

We have maintained detailed direct water contact observations in Ndombo during the first years of the $S$. mansoni epidemic in Northern Senegal. The analysis of this unique dataset, amounting to over 120,000 recorded contacts, is presented here. We quantified water contact activities in terms of frequency and duration, and described how these vary with age and sex. In this way, we aimed to determine whether water contact patterns in Ndombo were exceptional or comparable to those in traditional schistosomiasis endemic communities in subSaharan Africa. Moreover, we assessed the relationship between water contact- and infection intensity patterns to further elucidate the contribution of exposure to the transmission of schistosomiasis.

\section{Methods}

\section{Study site and population}

The study took place in Ndombo, a village situated 3 $\mathrm{km}$ south of the city of Richard Toll in the Delta of the Senegal River Basin (Northern Senegal). The village counts about 3000 inhabitants, mostly Wolof ethnic group of Muslim faith. The majority of the population works in rice farming, small-scale market gardening, fishing, or is employed in the nearby sugar cane estate. The climate in the area is arid and characterized by a hot dry season with temperatures up to $45^{\circ} \mathrm{C}$ (April to June), a hot and humid period (July to October), and a relatively cold dry season between November and April in which temperatures can drop to $10-15^{\circ} \mathrm{C}$. The village is situated along a man-made canal and marshland (Taouey) that connects the sugar cane plantations, the Senegal River, and an inland lake. The population depends largely on this water source for domestic, recreational as well as occupational purposes, and most water contact activities take place at five well-defined sites on the banks of the canal and the marshland (Figure 1).

This study is part of a larger investigation on schistosomiasis epidemiology, transmission and control in Senegal, for which approval was obtained from the ethical committees of the Leiden University Medical Centre, the Netherlands, the Institute of Tropical Medicine in Antwerp, Belgium, and the Ministry of Health in Dakar, Senegal, respectively.

\section{Data collection}

Direct observations of individual water contacts were carried out from September 1991 to September 1993 (25 months). The sites selected for the study were the main water contact sites in the village where most activities leading to schistosomiasis infection occurred (see Figure 1). Twelve observers with formal education were chosen among the villagers and submitted to one week of training before the start of the study. The water contact behavior of the whole population of Ndombo was observed from 6 a.m. till 7 p.m. (13 hours) seven days each month. For each site, the observers were divided into pairs. The first shift with the first observer was from 6 to 12.30 a.m., the second from 12.30 to 7 p.m. For the most crowded site (site II in Figure 1), two teams of observers were selected, whereby one team observed the males and the other team observed the females. A local supervisor randomly visited the observers several times per observation day to make sure that the observations were accurate and standardized.

Each individual entering the water was identified by the observer and recorded in a notebook by name, age, sex, type of water contact activity, time of entrance into, and exit out of the water. Nine different types of activities were recorded: a] (Dis)embarking: embarking or disembarking a boat to cross the stream; b] Small bath: small bath, ablution and/or drinking; c] Bathing: bathing with or without soap, swimming and/or playing; d] Collecting water: fetching water for domestic purposes; e] Household: doing laundry and/or dishes; f] Animals: watering and/or washing animals in the water; g] Private toilet: washing of genitals, bottom; h] Fishing: fishing related activities in or near the water; i] Irrigation: irrigation and/or removing vegetation from the water. If a range of activities, i.e. more than one type of activity, took place between time of entrance into the water and exit out of the water, these were noted down consecutively, and marked as combined activity. Among the water contact recordings of the total population, only those individuals belonging to the four studied cohorts were considered in our study. These cohorts consisted of random population samples of approximately 400 


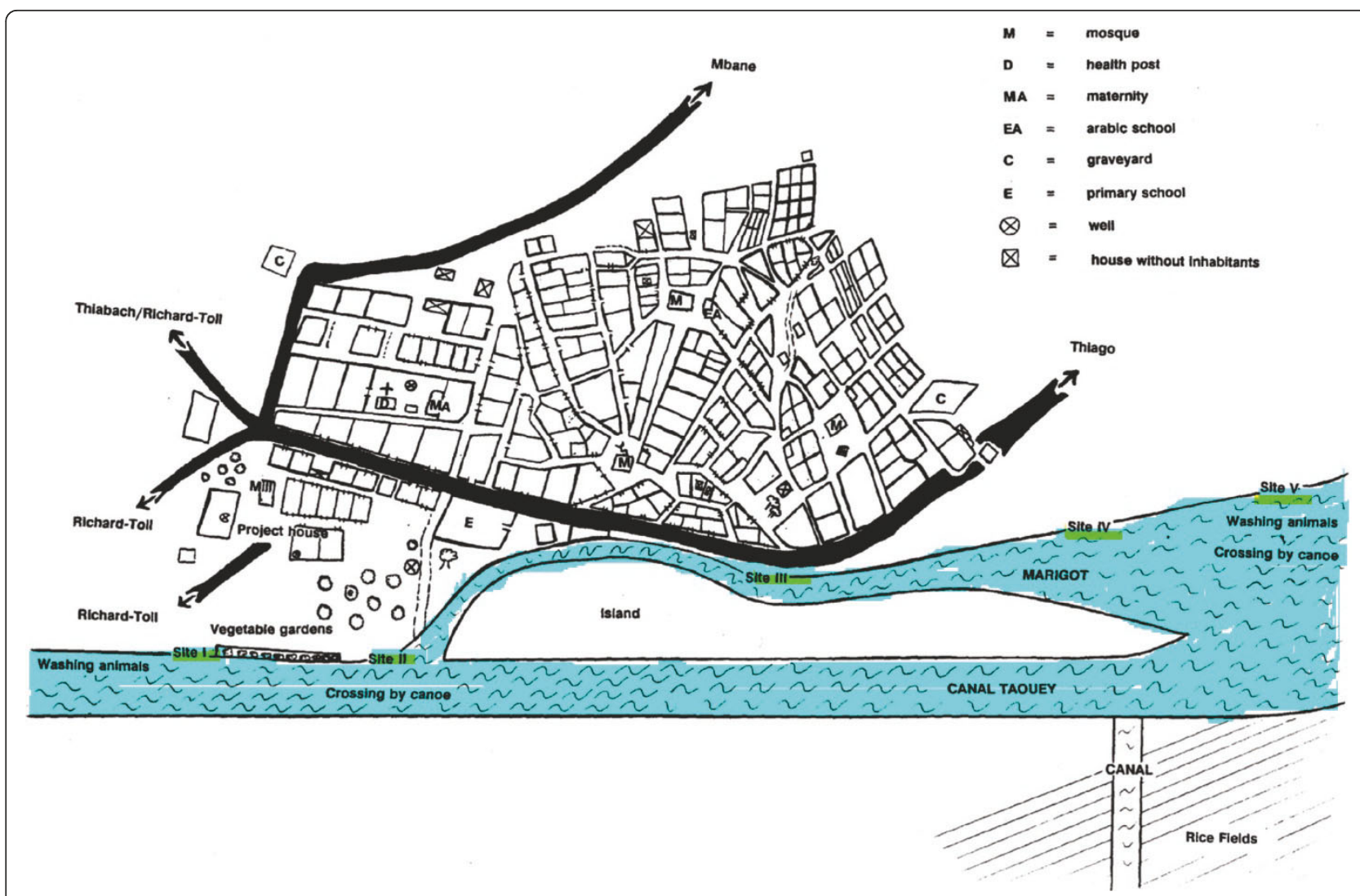

Figure 1 Main water contact sites in the village of Ndombo, Northern Senegal.

subjects each, selected at 8-month intervals between 1991 and 1994, and examined for S. mansoni infection by egg counts in stools, using the Kato-Katz method $[1,2]$. Their corresponding individual codes were recorded in the notebooks retrospectively. The data were entered daily into a Microsoft Excel database, and extensively checked for errors, suspicious values and outliers.

\section{Data analysis}

Two exposure indices were used, frequency and duration of water contact. Frequency was defined by the number of water contacts, irrespective of the (type of) activity. A range of two or more observed activities was considered as one water contact. Table 1 lists the single and combined activities which were used to determine frequencies. Duration was defined by the time spent in the water during a water contact activity. In case of a combination of two or more observed activities the most dominant was chosen, based on degree of exposure and/or duration of contact, or they were split up when one was not clearly dominant over the other (Figure 2). Table 2 shows the resulting total and average durations of activities.
Frequencies and durations of water contact data were further categorized per age group (0-9 years, 10-19 years, more than 20 years old) and sex. They were divided according to season (hot wet, hot dry, and cold dry), time of the day (divided into hourly intervals) and type of activity (see above). These exposure indices were averaged and related to intensity of infection, as expressed by the arithmetic mean eggs per gram feces (EPG), both pre-control and measured 1 year after treatment. Infection intensities (EPG pre-control and one year after treatment) for the six age/sex-categories were plotted against frequency and duration of water contact, and values of $\mathrm{R}$-squared were calculated, assuming a proportional association. Also, water contact values were adjusted for body surface (percentage of the body exposed related to a certain water contact activity, with a maximum of $100 \%$ for 'bathing') and time of day (reflecting the mean relative number of cercariae assumed to be in the water during that time, with a peak between 1 p.m. and 2 p.m. - assuming that $0.1 \%$ of cercariae were viable after $24 \mathrm{~h}$ ). These adjusting factors have previously been applied by Scott et al., who tested various assumptions regarding the relationship between water contact and exposure in a questionnaire-based 
Table 1 Overview of all 121,771 observed water contacts of the 1,651 members of four epidemiological cohorts in Ndombo, Northern Senegal, during 175 days (7 days in each of 25 successive months) of observations; first the frequency and duration of all nine single water contact activities are given, followed by the most frequently observed combined activities

\begin{tabular}{|c|c|c|c|c|}
\hline Activity & Description & Total duration (min) & Total count & Average duration (min) \\
\hline a & (Dis)embarking & 8858 & 4407 & 2.0 \\
\hline$b$ & Small bath & 11781 & 3670 & 3.2 \\
\hline C & Bathing & 617543 & 54844 & 11.3 \\
\hline$d$ & Collecting water & 55659 & 29141 & 1.9 \\
\hline e & Household & 91404 & 3282 & 27.9 \\
\hline f & Animals & 13353 & 1215 & 11.0 \\
\hline$g$ & Private toilet & 510 & 216 & 2.4 \\
\hline $\mathrm{h}$ & Fishing & 9353 & 383 & 24.4 \\
\hline i & Irrigation & 11979 & 1572 & 7.6 \\
\hline Subtotal & & 820439 & 98730 & 8.3 \\
\hline$a+b$ & (Dis)embarking + small bath & 957 & 368 & 2.6 \\
\hline$b+d$ & Small bath + collecting water & 5018 & 945 & 5.3 \\
\hline$b+g$ & Small bath + private toilet & 368 & 102 & 3.6 \\
\hline$c+d$ & Bathing + collecting water & 213561 & 14285 & 15.0 \\
\hline$c+d+e$ & Bathing + collecting water + household & 6711 & 203 & 33.1 \\
\hline$c+e$ & Bathing + household & 144252 & 3740 & 38.6 \\
\hline$c+f$ & Bathing + animals & 18889 & 1221 & 15.5 \\
\hline$c+h$ & Bathing + fishing & 2440 & 81 & 30.1 \\
\hline$c+i$ & Bathing + irrigation & 10331 & 483 & 21.4 \\
\hline$d+e$ & Collecting water + household & 34494 & 1453 & 23.7 \\
\hline$d+g$ & Collecting water + private toilet & 317 & 120 & 2.6 \\
\hline Other & Combined activities with $<50$ observations & 208 & 40 & 5.2 \\
\hline Subtotal & & 437546 & 23041 & 19.0 \\
\hline \multirow[t]{3}{*}{ Total } & All activities & 1257985 & 121771 & 10.3 \\
\hline & Per individual & 762 & 74 & \\
\hline & Per individual per day & 4.4 & 0.42 & \\
\hline
\end{tabular}

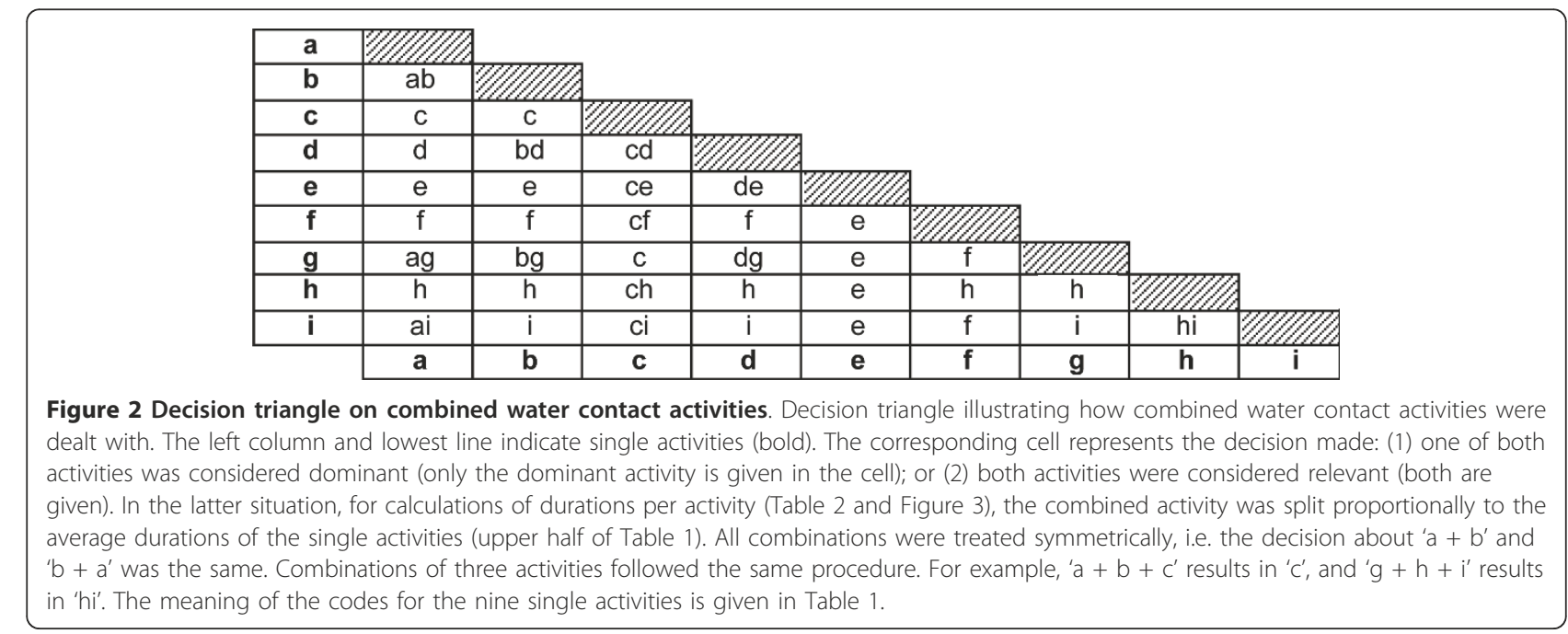


Table 2 Overview of the total and average durations of the nine types of water contact, after processing of the combined activities

\begin{tabular}{llrrr}
\hline Activity & Description & $\begin{array}{r}\text { Total } \\
\text { duration } \\
\text { (min) }\end{array}$ & $\begin{array}{r}\text { Total } \\
\text { count }\end{array}$ & $\begin{array}{r}\text { Average } \\
\text { duration (min) }\end{array}$ \\
\hline a & (Dis)embarking & 9255 & 4802 & 1.9 \\
b & Small bath & 15755 & 5100 & 3.1 \\
c & Bathing & 859996 & 74857 & 11.5 \\
d & Collecting & 91184 & 46158 & 2.0 \\
& Water & & & 26.6 \\
e & Household & 230961 & 8678 & 9.3 \\
f & Animals & 22683 & 2436 & 1.9 \\
g & Private toilet & 882 & 473 & 23.8 \\
h & Fishing & 11076 & 466 & 7.9 \\
i & Irrigation & 16194 & 2060 & 8.7 \\
Total & All activities & 1257985 & 145015 & \\
& Per individual & 762 & 88 & \\
& Per individual & 4.4 & 0.50 &
\end{tabular}

See Table 1 for the number of subjects and observation time.

study in Northern Senegal [5]. An improvement of the fit was determined by the percentage reduction of the residual variance (unexplained variation) for the model with adjustment as compared to the one without.

\section{Results}

The number of recorded contacts was 121,771 (Table 1) with 1,257,985 minutes of observed water contact spread over 2 years (September 1991 - September 1993). Bathing/swimming appeared to be the main activity, both in terms of duration and frequency, followed by household activities. Some categories took relatively long, but occurred rarely, such as fishing; for other activities, such as collecting water, it was the other way around (Table 2). Fishing, (dis)embarking, small bath, animals, private toilet and irrigation played a negligible role, both in terms of frequency and duration.

Figure 3 and 4 show the duration and frequency of water contact per season, age and sex. Although in the hot dry season water contacts were slightly more intense than for the other seasons, patterns of both duration and frequency depend much more on age than on the season. In the age group of 10-19 years, longer and more frequent water contact was observed than in the other age groups. Women showed substantially more and longer water contact than men; for the older age groups (10-19 and more than 20 years), duration and frequency of water contact in women were even twice that of men. Female adolescents (10-19 years) showed the most intense water contact, which is mainly due to collecting water more often and a longer time spent on household activities. Most intense water contact occurred between noon and 2 p.m. for men; for women two distinct peaks were observed, one between 8 and 10 a.m., and one between 2 and 5 p.m.

Figure 5 shows for each age- and sex group the infection intensity in relation to duration and frequency of water contact. It is clear that EPG-values (both pre-control and 1 year after treatment) are not linearly related with water contact. Especially adult females had lower egg counts than would be expected from the duration and frequency of their water contacts, while male adolescents appeared to have the highest EPG/water contact ratio. The average number of water contacts per person per day in this population was 0.42 ; the average time spent in the water per person per day was 4.3 minutes.

Figure 6 shows for each age- and sex group the infection intensity in relation to duration and frequency of water contact, after adjustment for body surface and time of day of contact. Both proxies for exposure, especially frequency, showed a better fit with intensities of infection when adjusting for these two factors (Figure 6 vs Figure 5). Nevertheless, the relationship between infection and water contact patterns still deviated from a clear proportional one, especially in women.

\section{Discussion}

After the outbreak of a S. mansoni epidemic, extremely high infection rates and typical endemic-like age-related infection patterns were observed in Ndombo, Senegal. The main justification of the current study was to determine the contribution of water contact behavior to these exceptional observations. Descriptive analysis of the water contact activities showed that bathing was the main activity, followed by household activities; water contacts peaked in adolescents; women spent almost twice as much time at the water than men; water contacts were more intense in the afternoon than in the morning, with sex-specific intensity peaks; and frequency and duration of water contact depended on age and sex rather than season. These findings are not unusual and have been described before in various other settings $[7,10,16,30,33-36]$. Since infected snails were attested to be present throughout the year [37] and marked seasonal variations of water contact behavior appeared to be absent, transmission in this area is likely to be perennial.

Also in terms of the number of water contacts per person per day, our results in Northern Senegal did not show marked differences with other schistosomiasis endemic countries where intensive observational water contact studies have been performed. Indeed, our finding of an average of 0.42 contacts per person per day is within the range of Fulford et al. [10], who reported a mean annual frequency of 12.8 to 162 water contacts/ person among seven $S$. mansoni endemic communities 


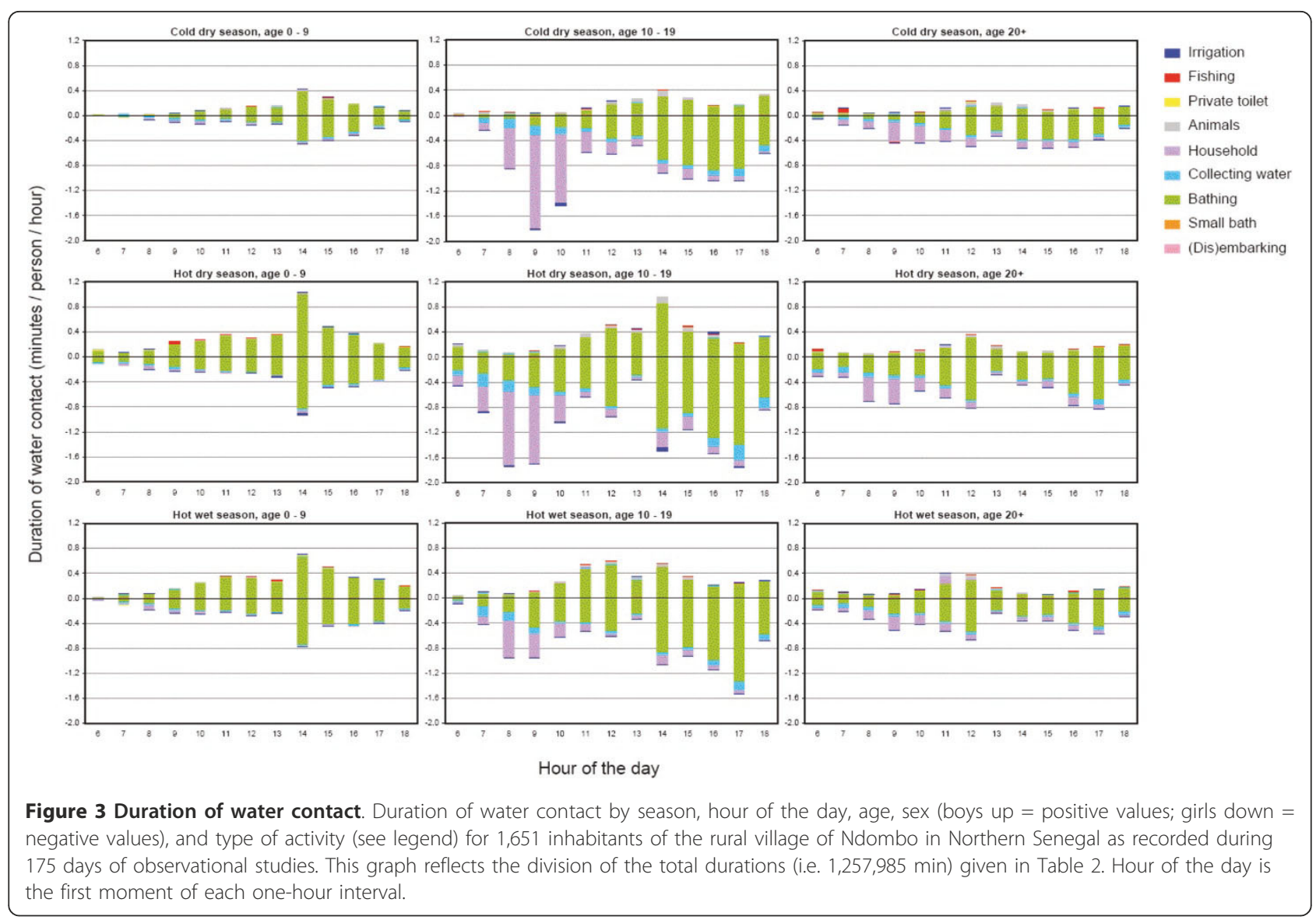

in Kenya, which is 0.04 to 0.44 contacts/person/day (median 0.17). Exact average water contact durations for these communities were not reported, but from the graphs it can be deduced that this was about 880 minutes/person annually, and thus 2.4 minutes per day. Again, this is of the same order of magnitude as the average duration of 4.3 minutes spent in the water per day as presented here for Northern Senegal. Chandiwana \& Woolhouse [38] reported a mean rate of water contact of 0.43 contacts/person/day (ranging from zero to 3.3 contacts/person/day), in a S. haematobium endemic area in Zimbabwe, which is remarkably similar to our values for Senegal. Other water contact studies based on direct observations used different exposure indices, which precludes straightforward comparison $[32,39,40]$. Nevertheless, from the available observational water contact studies we can conclude that the water contact levels in Ndombo are not exceptionally high and thus cannot explain the extremely high infection intensities in this area as compared to the other studies.

Both infection- and water contact patterns in this community were found to be clearly age-and sex-related. Looking at these patterns more closely however, we found that in the respective age- and sex groups more or longer water contact did not unequivocally lead to high infection intensities (Figure $5+6$ ). In the oldest two age groups, women showed substantially more and longer water contact than men, while infection levels were comparable. An explanation for this finding could be that male water-related activities entail relatively intense water contact. Indeed, the main male activity was bathing, which can be considered a more risky behaviour in terms of body exposure as compared to typical female activities such as collecting water or doing laundry/dishes. Also the degree of using soap, which may have a 'cercaricidal' effect [10], for washing clothes and/or bathing may have influenced infection intensities in women and men in different ways. Moreover, in men most intense water contact occurred between noon and 2 p.m., the part of the day when cercarial emission has been reported to be highest in the Senegal River Basin [41], while women's water contact peaked in the morning and afternoon. Indeed, after adjusting for body surface and time of day, the association between water contact and intensities of infection appeared to be stronger than without including these factors, but differences in this relationship across the demographic groups remained (Figure 6). In addition, 


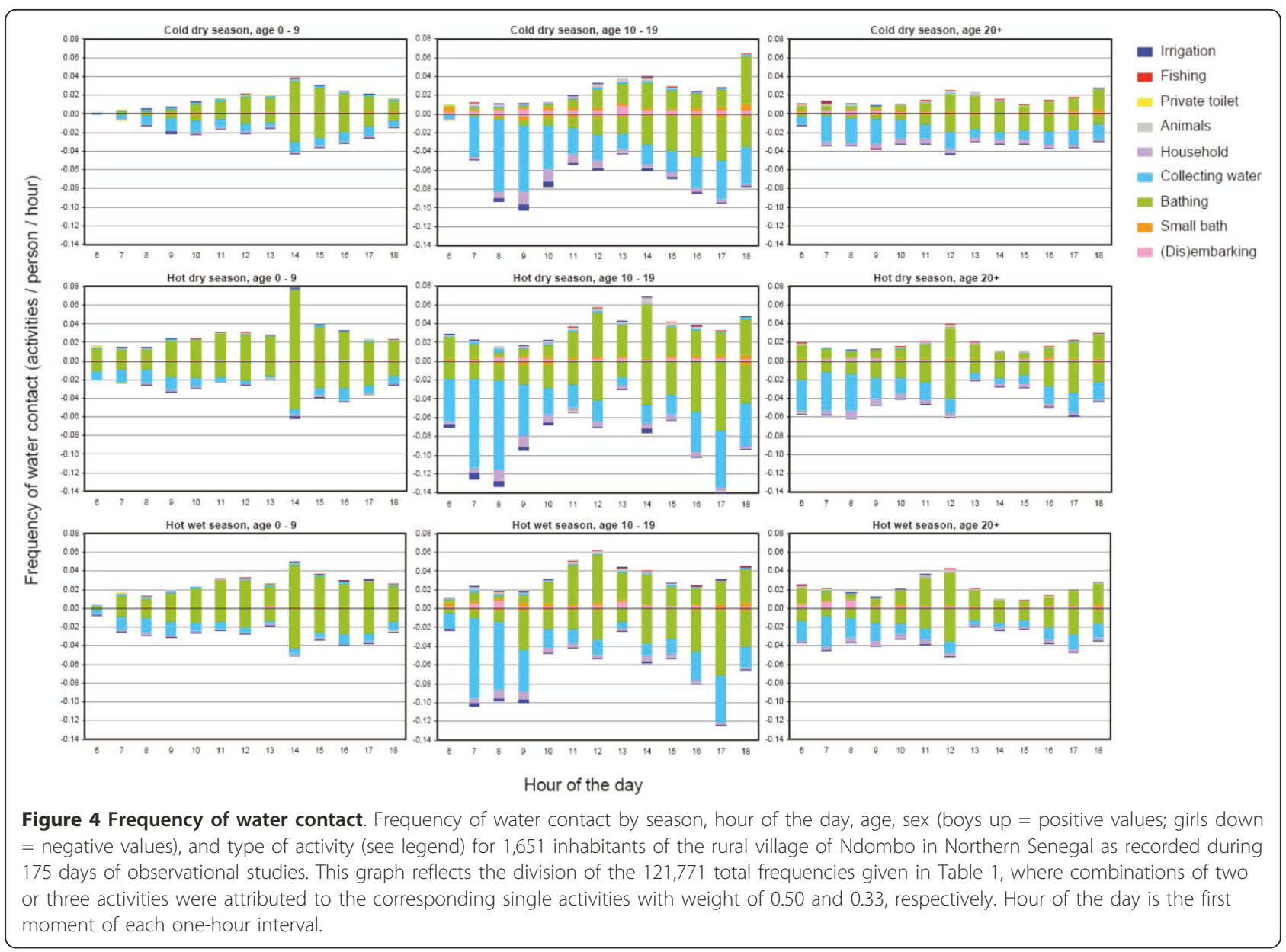

male adolescents showed much higher infection levels than the other male age groups, while they did not bath significantly more or longer than young or adult men, nor at different times of the day. Another hypothetical explanation may be that certain typical male activities have not been captured, as these may have taken place outside the designated observation time or sites (e.g. fishing). However, we have no indications for such an effect in males only.

Despite observed differences in infection- and water contact patterns depending on age and sex, exposure appears not to be the only factor of importance in determining intensity of infection before or one year after treatment in this Schistosoma epidemic focus. Similar conclusions resulted from studies in stable endemic situations $[11,39,42,43]$. A few have found some relationship between water contact and infection intensity, although not very strong/convincing $[12,38,44]$. It should be noted that for any of these studies, including ours, it cannot be excluded that exposure factors other than those taken into account, may have somehow contributed to the observed age- and sex-related differences in infection levels [5,39]. In the specific case of Ndombo, very high numbers and infection rates of Biomphalaria pfeifferi, the snail intermediate host of S. mansoni, were found at the start of the epidemic [2], which could also have (partly) accounted for the extremely high $S$. mansoni infection intensities of the community. An obvious alternative explanation other than exposure would be the absence of acquired immunity in this recently exposed, supposedly non-immune community, but this does not correspond with the observed endemic-like age-related infection patterns in this community $[1,3]$.

For women, the ratio of infection intensity to water contact (i.e. the slope of a hypothetical line from the origin to a point) in Figure 5 and - to a lesser extent - Figure 6 decreased with age, suggesting an increasing degree of resistance with age. In an epidemic focus like Ndombo, immunity should not, or at most partially, have developed at the time of the data collection. Thus, this resistance is more likely to be due to some other age-related, innate factor $[2,4,5]$. In men, however, this pattern seemed to be absent, with the youngest age group showing a slightly lower ratio than the older 

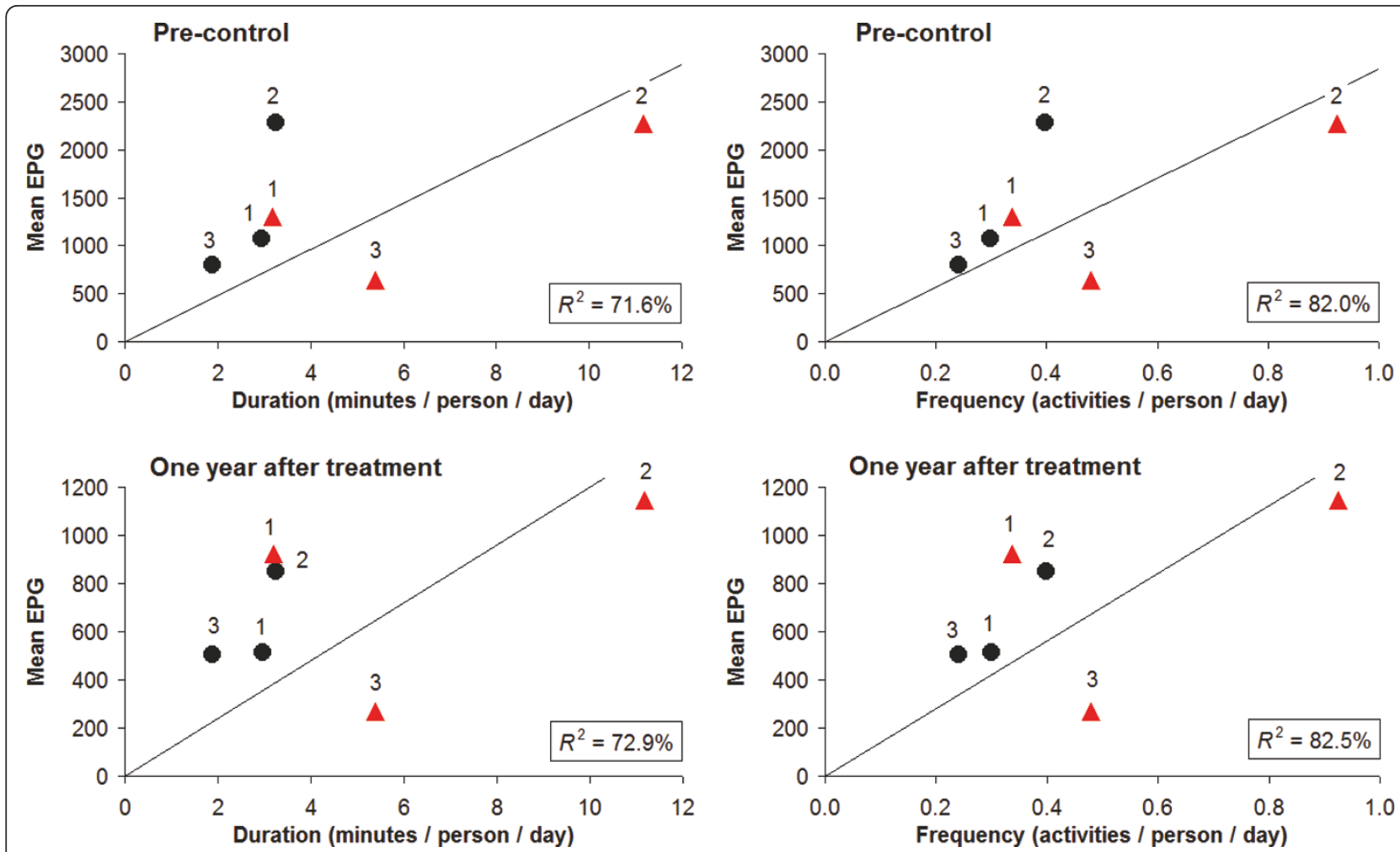

Figure 5 Infection intensity in relation to duration and frequency of water contact. Infection intensity (arithmetic mean EPG, both precontrol and one year after treatment) in relation to duration and frequency of water contact, for six demographic groups based on three age categories and both sexes. The durations are the accumulation over season, hour of the day, and type of activity of the values for each demographic group in Figure 3. Similarly, the frequencies are the accumulation of values in Figure 4. Black dots = males, red triangles = females; $1=0-9$ years, $2=10-19$ years, $3=20$ years and above.

groups, particularly after adjusting for body surface and time of day (Figure 6). As yet, there is no biological evidence that could explain why such resistance would only occur in adult women and not in adult men. Postpubertal hormonal or other (both age- and sex-related) factors may play a role. For example, Fulford et al. [45] suggested that gonadal steroids affecting the immune system may lie behind the common observation, originally made by Butterworth et al. [46], that women are usually infected less heavily than men yet generally have more water contact.

A non-proportional relationship between egg counts and water contact may also indicate that egg production is suppressed in individuals with higher water contact, and thus suggesting some form of density-dependence. For example, density-dependent fecundity has been widely implicated as a major regulatory force in maintaining helminth population stability, and is generally considered to result either from competition between parasites for host resources or from immunological control [47]. The phenomenon is still controversial for schistosomiasis [48-54]. And yet again, we cannot explain why such density-dependence would only occur in women and not in men.

To our knowledge, this is the largest dataset published so far of directly observed recorded water contacts, spanning a two year time period in the early years of an S. mansoni epidemic. Direct water contact observations have more quantitative and qualitative value than water contact information based on questionnaires, which are easy to perform but have inherent well-known limitations such as overreporting, recall bias and information bias $[55,56]$. This is illustrated by a questionnaire-based study in four villages in the same $S$. mansoni affected area as Ndombo [5]. This study reported a mean of 4.4 water contacts per day with a median duration of 57 min per day, which is in sharp contrast with the relatively low numbers found in the present study. It has been noted before that levels and patterns of contact can vary dramatically between culturally similar communities, and even within a single village $[10,36]$, but these extreme numbers are more likely to be due to the way the water contact information was collected [56]. 

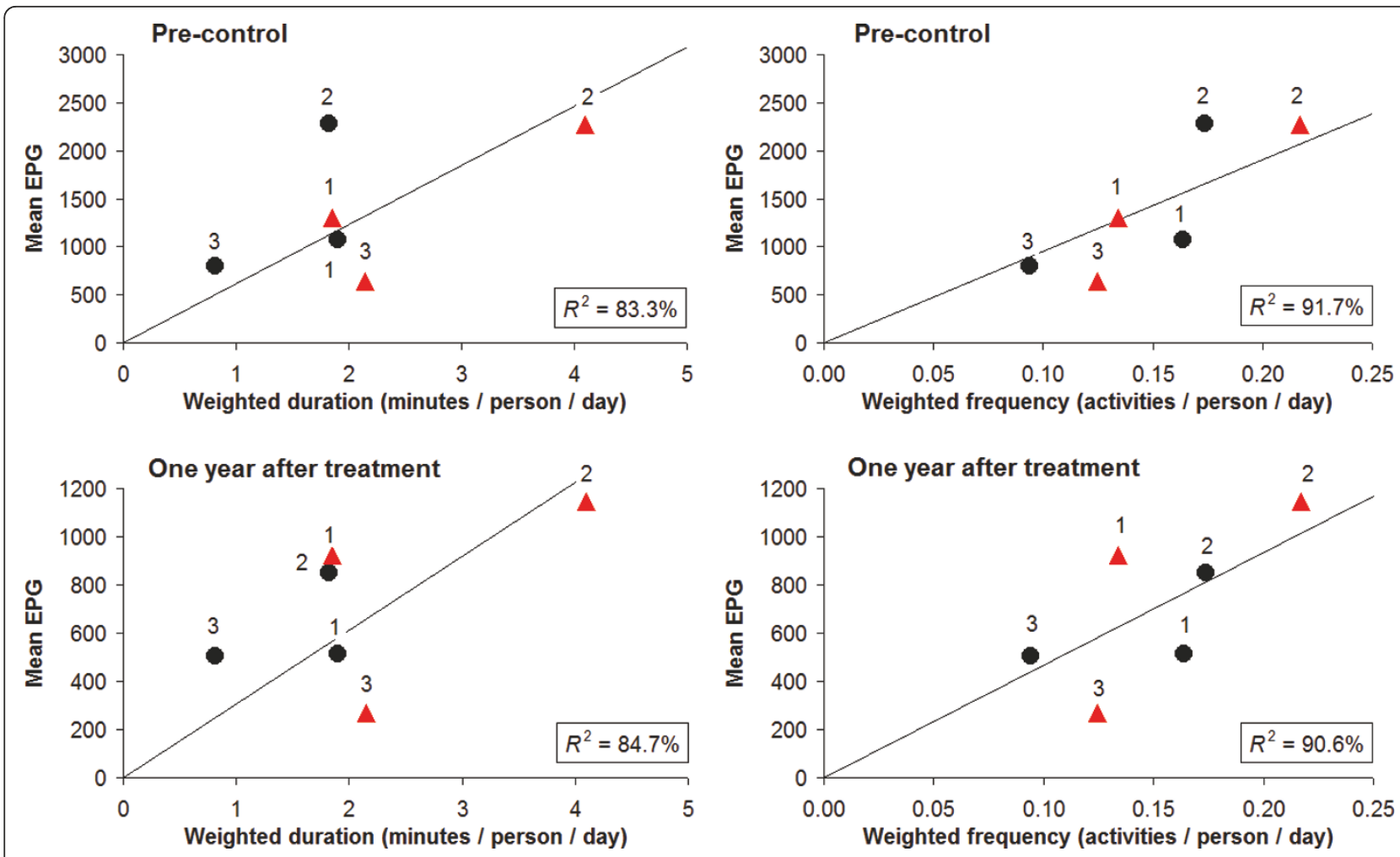

Figure 6 Infection intensity in relation to 'weighed' duration and frequency of water contact. Similar as Figure 5, but then adjusted for body surface and time of day (reflecting cercarial density), as previously described by Scott et al. [5]. As compared to the unadjusted model (Figure 5), the residual variance (unexplained variation) of the adjusted model reduced by $41 \%$ (duration) and 54\% (frequency) pre-control, and $44 \%$ (duration) and $46 \%$ (frequency) one year after treatment, respectively.

A few limitations are present in this study. All water contact measurement tools, including direct water contact observations are only an indirect measure of true exposure, i.e. exposure to infectious cercariae. It is impossible to determine true exposure [10]. Different authors have approximated and compared exposure from water contact behavior in various ways [5,10,32,34,39,57-59], but the possibility will always remain that their and our conclusions are based on an inadequate understanding of how water contact translates into exposure. Moreover, direct water contact observations may be subject to 'observer effect', occurring when subjects alter their behaviour because an observer is present. For example, we did not observe a single act of direct defecation into the stream, even though such an activity would occasionally be expected, at least for children, to explain the intense transmission of $S$. mansoni in this area [60]. Also, direct observation tends to underreport water contacts taking place outside the limits of observation time or of observation sites [30]. For that reason, some fishing-related contacts may have gone unnoticed, as fishing by its nature is much dispersed [36]. The same holds for occupational activities in the adjacent rice and sugar cane fields. Last but not least, exposure does not depend on human behaviour alone, and should ideally be analysed in relation to snail studies or cercariometry.

\section{Conclusion}

The water contact levels in Ndombo are not exceptionally high and thus cannot explain the extremely high infection intensities as observed in this area during the S. mansoni epidemic. Absence of an effective acquired immunity could play a role, but this is in contrast with the strongly decreasing ratio of infection intensity/water contact with age that we found for women, as well as with previous immuno-epidemiological studies in the same area [1,3]. Although both infection- and water contact patterns in this community were found to be age- and sex-related, there is no clear proportional relationship between exposure and infection intensity, neither before nor one year after treatment in this Schistosoma epidemic focus. The finding that water contact and infection levels do not unambiguously correspond with each other, irrespective of the assumptions made regarding the relationship between water contact behaviour and exposure, indicates that in this population other factors than only exposure play an important role 
in determining intensity of infection. Further research is needed, with respect to the translation of water contact data into actual exposure, as well as the relation between exposure and actual Schistosoma infection at the individual level.

\section{Acknowledgements}

We gratefully acknowledge the population of Ndombo, and all water contact observers, data entry clerks and cleaners for their essential contributions to the study. We thank Professor J.D.F. Habbema for his critical comments on the manuscript.

\section{Author details}

'Prince Leopold Institute of Tropical Medicine, Antwerp, Belgium.

${ }^{2}$ Department of Public Health, Erasmus MC, University Medical Center Rotterdam, The Netherlands. ${ }^{3}$ Région Médicale de St Louis, St Louis, Senegal. ${ }^{4}$ Department of Medical Microbiology, Virology Section, Radboud University Nijmegen Medical Centre, Nijmegen, The Netherlands.

\section{Authors' contributions}

SS contributed to the design of the study, participated in the data collection and data analysis, and helped to draft the manuscript. SJDV designed and coordinated the data analysis, and drafted the manuscript. FS participated in the design and coordination of the study, and revised the manuscript. KV participated in the data analysis and the revision of the manuscript. BG conceived of the study, participated in its design and coordination, and revised the manuscript. KP contributed to the design and analysis of the data, and drafted the manuscript. All authors read and approved the final manuscript.

\section{Competing interests}

The authors declare that they have no competing interests.

Received: 9 July 2010 Accepted: 18 July 2011 Published: 18 July 2011

\section{References}

1. Stelma FF, Talla I, Polman K, Niang M, Sturrock RF, Deelder AM, Gryseels B: Epidemiology of Schistosoma mansoni infection in recently exposed community in Northern Senegal. Am J Trop Med Hyg 1993, 49:701-706.

2. Gryseels B, Stelma FF, Talla I, van Dam GJ, Polman K, Sow S, Diaw M, Sturrock RF, Doehring-Schwerdtfeger E, Kardorff R, Decam C, Niang M, Deelder AM: Epidemiology, immunology and chemotherapy of Schistosoma mansoni infections in a recently exposed community in Senegal. Trop Geogr Med 1994, 46:209-219.

3. Polman K, Stelma FF, Gryseels B, Van Dam GJ, Talla I, Niang M, Van Lieshout L, Deelder AM: Epidemiological application of circulating antigen detection in a recent Schistosoma mansoni focus in northern Senegal. Am J Trop Med Hyg 1995, 53:152-157.

4. Polman K, Stelma FF, Le Cessie S, De Vlas SJ, Falcão Ferreira ST, Talla I, Deelder AM, Gryseels B: Evaluation of the patterns of Schistosoma mansoni infection and re-infection in Senegal, from faecal egg counts and serum concentrations of circulating anodic antigen. Ann Trop Med Parasitol 2002, 7:679-689.

5. Scott JT, Diakhaté M, Vereecken K, Fall A, Diop M, Ly A, De Clercq D, De Vlas SJ, Berkvens D, Kestens L, Gryseels B: Human water contacts patterns in Schistosoma mansoni epidemic foci in northern Senegal change according to age, sex and place of residence, but are not related to intensity of infection. Trop Med Int Health 2003, 8:100-108.

6. Bundy DAP, Blumenthal UJ: Human behavior and the epidemiology of helminth infections: the role of behavior in exposure to infection. In Parasitism and Host Behavior. Edited by: Barnard CJ, Behnke JM. Taylor 1990:364-389.

7. Coulibaly G, Diallo M, Madsen H, Dabo A, Traoré M, Keita S: Comparison of schistosome transmission in a single - and a double - cropped area in the rice irrigation scheme, 'Office du Niger', Mali. Acta Trop 2004, 91:15-25.

8. Dalton PR, Pole D: Water-contact patterns in relation to Schistosoma haematobium infection. Bull World Health Organ 1978, 56:417-426.
9. El Katsha S, Watts S: Schistosomiasis in two Nile delta villages: an anthropological perspective. Trop Med Int Health 1997, 2:846-854.

10. Fulford AJ, Ouma JH, Kariuki HC, Thiongo FW, Klumpp R, Kloos H, Sturrock RF, Butterworth AE: Water contact observations in Kenyan communities endemic for schistosomiasis: methodology and patterns of behaviour. Parasitology 1996, 113:223-241.

11. Kabatereine NB, Vennervald BJ, Ouma JH, Kemijumbi J, Butterworth AE, Dunne DW, Fulford AJ: Adult resistance to schistosomiasis mansoni: agedependence of reinfection remains constant in communities with diverse exposure patterns. Parasitology 1999, 118:101-105.

12. Kloos H, Higashi Gl, Cattani JA, Schlinski VD, Mansour NS, Murrel KD: Water contact behavior and schistosomiasis in an upper Egyptian village. Soc Sci Med 1983, 17:545-562

13. Kvalsvig JD, Schutte CHJ: The role of human water contact patterns in the transmission of schistosomiasis in an informal settlement near a major industrial area. Ann Trop Med Parasitol 1986, 80:13-26.

14. Ofoezie JE, Christensen NO, Madsen H: Water-contact patterns and behavioral knowledge of schistosomiasis in south-west Nigeria. J Biosoc Sci 1998, 30:245-259.

15. Tayo MA, Pugh RNH, Bradley AK: Mulumfashi endemic diseases research project, XI. Water-contact activities in the schistosomiasis study area. Ann Trop Med Parasitol 1980, 74:347-354.

16. Watts S, Khallaayoune K, Bensefia R, Laamrani H, Gryseels B: The study of human behavior and schistosomiasis transmission in an irrigated area in Morocco. Soc Sci Med 1998, 46:755-765.

17. World Health Organization: Workshop on the role of human-water contact in schistosomiasis transmission. St Lucia 1979, TDR/SER-HWC/79.3.

18. Woolhouse ME, Etard JF, Dietz K, Chandiwana SK, Hagan P: Heterogeneities in schistosome transmission dynamics and control. Parasitology 1998, 117:475-482.

19. Barbosa CS, Barbosa FS: Schistosomiasis epidemiological patterns in a community of small farmers in Pernambuco State, Brazil. Cad Saude Publica 1998, 14:129-137.

20. Barreto ML: Use of risk factors obtained by questionnaires in the screening for Schistosoma mansoni infection. Am J Trop Med Hyg 1993, 48:742-747.

21. Coura-Filho P, Rocha RS, Farah MW, da Silva GC, Katz N: Identification of factors and groups at risk of infection with Schistosoma mansoni: a strategy for the implementation of control measures? Rev Inst Med Trop Sao Paulo 1994, 36:245-253.

22. Da Silva AA, Cutrim RN, de Brittoe Alves MT, Coimbra LC, Tonia SR, Borges DP: Water contact patterns and risks factors for Schistosoma mansoni infection in a rural village of northern Brazil. Rev Inst Med Trop Sao Paulo 1997, 39:91-96.

23. Lima e Costa MF, Magalhães MH, Rocha RS, Antunes CM, Katz N: Water contact patterns and socio-economic variables in the epidemiology of schistosomiasis mansoni in an endemic area in Brazil. Bull World Health Organ 1987, 65:57-66.

24. Lima e Costa MF, Rocha RS, Firmo JO, Guerra HL, Passos VA, Katz N Questionnaires in the screening for Schistosoma mansoni infection: a study of socio demographic and water contact variables in four communities in Brazil. Rev Inst Med Trop Sao Paulo 1998, 40:93-99.

25. Moza PG, Pieri OS, Barbosa CS, Rey L: Socio-demographic and behavioral factors related to schistosomiasis in a rural village of the sugar cane belt in Pernambuco State, Brazil. Cad Saude Publica 1998, 14:107-115.

26. Firmo JO, Lima Costa MF, Guerra HL, Rocha RS: Urban schistosomiasis morbidity, socio-demographic characteristics and water contact patterns predictive of infection. Int J Epidemiol 1996, 25:1292-1300.

27. Ximenes RA, Southgate B, Smith PG, Guimaraes Neto L: Social environment, behavior and schistosomiasis in an urban population in northern Brazil. Rev Panam Salud Publica 2001, 9:13-22.

28. Brinkmann UK, Korte R, Schmidt-Ehry B: The distribution and spread of schistosomiasis in relation to water resources development in Mali. Trop Med Parasitol 1988, 39:182-185.

29. Chandiwana SK: Seasonal patterns in water contact and the influence of water availability on water contact activities in two schistosomiasis endemic areas in Zimbabwe. Cent Afr J Med 1987, 33:8-15.

30. Gazzinelli A, Bethony J, Fraga LA, LoVerde PT, Corréa-Oliveira R, Kloos H: Exposure to Schistosoma mansoni infection in a rural area of Brazil. I: water contact. Trop Med Int Health 2001, 6:126-135. 
31. Bethony J, Williams JT, Kloos H, Blangero J, Alves-Fraga L, Buck G, Michalek A, Williams-Blangero S, LoVerder PT, Corréa-Oliveira R, Gazzinelli A: Exposure to Schistosoma mansoni infection in a rural area in Brazil. II. household risk factors. Trop Med Int Health 2001, 6:136-145.

32. Woolhouse ME, Mutapi F, Ndhlovu PD, Chandiwana SK, Hagan P: Exposure, infection and immune responses to Schistosoma haematobium in young children. Parasitology 2000, 120:37-44

33. Rudge JW, Stothard JR, Basáñez MG, Mgeni AF, Khamis IS, Khamis AN, Rollinson D: Micro-epidemiology of urinary schistosomiasis in Zanzibar: Local risk factors associated with distribution of infections among schoolchildren and relevance for control. Acta Trop 2008, 105:45-54

34. Kloos H, Rodrigues JC, Pereira WR, Velásquez-Meléndez G, Loverde P, Corréa- Oliveira R, Gazzinelli A: Combined methods for the study of water contact behaviour in a rural schistosomiasis-endemic area in Brazil. Acta Trop 2006, 97:31-41.

35. Ndassa A, Mimpfoundi R, Gake B, Paul Martin MV, Poste B: Risk factors for human schistosomiasis in the Upper Benue valley, in northern Cameroon. Ann Trop Med Parasitol 2007, 101:469-477.

36. Pinot de Moira A, Fulford AJ, Kabatereine NB, Kazibwe F, Ouma JH, Dunne DW, Booth M: Microgeographical and tribal variations in water contact and Schistosoma mansoni exposure within a Ugandan fishing community. Trop Med Int Health 2007, 12:724-735.

37. Sturrock RF, Diaw OT, Talla I, Niang M, Piau JP, Capron A: Seasonality in the transmission of schistosomiasis and in populations of its snail intermediate hosts in and around a sugar irrigation scheme at Richard Toll, Senegal. Parasitology 2001, 123:77-89.

38. Chandiwana SK, Woolhouse ME: Heterogeneities in water contact patterns and the epidemiology of Schistosoma haematobium. Parasitology 1991, 103:363-370.

39. Wilkins HA, Blumenthal UJ, Hagan P, Hayes RJ, Tulloch S: Resistance to reinfection after treatment of urinary schistosomiasis. Trans $R$ Soc Trop Med Hyg 1987, 81:29-35

40. Demeure CE, Rihet $P$, Abel L, Ouattara M, Bourgois A, Dessein AJ: Resistance to Schistosoma mansoni in humans- influence of the $\lg E / \operatorname{lgG} 4$ balance and lgG2 in immunity to reinfection after chemotherapy. $J$ Infect Dis 1993, 168:1000-1008.

41. Southgate $V$, Tchuem Tchuenté $L A$, Sène $M$, De Clercq $D$, Théron $A$, Jourdane J, Webster BL, Rollinson D, Grysels B, Vercruysse J: Studies on the biology of schistosomiasis with emphasis on the Senegal River Basin Mem Inst Oswaldo Cruz 2001, 96:75-78.

42. Butterworth AE, Fulford AJ, Dunne DW, Ouma JH, Sturrock RF: Longitudinal studies on human schistosomiasis. Philos Trans R Soc Lond B Biol Sci 1988, 321:495-511.

43. Hagan P: Reinfection, exposure and immunity in human schistosomiasis. Parasitol Today 1992, 8:12-16.

44. Kloos H, Gazzinelli A, Van Zuyle P: Microgeographical patterns of schistosomiasis and water contact behaviour; examples from Africa and Brazil. Mem Inst Oswaldo Cruz 1998, 93:37-50.

45. Fulford AJ, Webster M, Ouma JH, Kimani G, Dunne DW: Puberty and agerelated changes in susceptibility to schistosome Infection. Parasitol Today $1998,14: 23-26$

46. Butterworth AE, Dalton PR, Dunne DW, Mugambi M, Ouma JH, Richardson BA, Arap Siongok TK, Sturrock RF: Immunity after treatment of human schistosomiasis mansoni. I. Study design, pretreatment observations and the results of treatment. Trans $R$ Soc Trop Med Hyg 1984, 78:108-123.

47. Anderson RM, May RM: Helminth infections of humans: mathematical models, population dynamics, and control. Adv Parasitol 1985, 24:1-101.

48. Cheever AW, Kamel IA, Elwi AM, Mosimann JE, Danner R: Schistosoma mansoni and S. haematobium infections in Egypt. II Quantitative parasitological findings at necropsy. Am J Trop Med Hyg 1977, 26:702-716.

49. Medley G, Anderson RM: Density-dependent fecundity in Schistosoma mansoni infections in man. Trans R Soc Trop Med Hyg 1985, 79:532-534.

50. Cheever AW: Density-dependent fecundity in Schistosoma mansoni infections in man: a reply. Trans $R$ Soc Trop Med Hyg 1986, 80:991-992.

51. Wertheimer SP, Vermund SH, Lumey LH, Singer B: Lack of demonstrable density-dependent fecundity of schistosomiasis mansoni: analyses of Egyption quantitative human autopsies. Am J Trop Med Hyg 1987, 37:79-84.

52. Gryseels B, De Vlas SJ: Worm burdens in schistosome infections. Parasitol Today 1996, 12:115-119.
53. Polman K, De Vlas SJ, Gryseels B, Deelder AM: Relating serum circulating anodic antigens to faecal egg counts in Schistosoma mansoni infections: a modelling approach. Parasitology 2000, 121:601-610.

54. Polman K, De Vlas SJ, Van Lieshout L, Deelder AM, Gryseels B: Evaluation of density-dependent fecundity in human Schistosoma mansoni infections by relating egg counts to circulating antigens through Deming regression. Parasitology 2001, 122:161-167.

55. Friedman JF, Kurtis JD, McGarvey ST, Fraga AL, Silveira A, Pizziolo V, Gazzinelli G, LoVerde P, Corréa-Oliveira R: Comparison of self-reported and observed water contact in an S. mansoni endemic village in Brazil. Acta Trop 2001, 78:251-259.

56. Payne G, Carabin H, Tallo V, Alday P, Gonzalez R, Joseph L, Olveda R, McGarvey ST: Concurrent comparison of three water contact measurement tools in four endemic villages of the Philippines. The schistosomiasis transmission ecology in the Philippines project (STEP). Trop Med Int Health 2006, 11:834-842.

57. Hagan P, Wilkins HA, Blumenthal UJ, Hayes RJ, Greenwood BM: Eosinophilia and resistance to Schistosoma haematobium in man. Parasite Immunol 1985, 7:625-632.

58. Sama MT, Ratard RC: Water contact and schistosomiasis infection in Kumba, south-western Cameroon. Ann Trop Med Parasitol 1994, 88:629-634.

59. Bethony J, Williams JT, Brooker S, Gazzinelli A, Gazzinelli MF, LoVerde PT, Corréa-Oliveira R, Kloos H: Exposure to Schistosoma mansoni infection in a rural area in Brazil. Part III: household aggregation of water-contact behaviour. Trop Med Int Health 2004, 9:381-389.

60. Sow S, Polman K, Vereecken K, Vercruysse J, Gryseels B, De Vlas SJ: The role of hygienic bathing after defecation in the transmission of Schistosoma mansoni. Trans R Soc Trop Med Hyg 2008, 102:542-547.

\section{Pre-publication history}

The pre-publication history for this paper can be accessed here: http://www.biomedcentral.com/1471-2334/11/198/prepub

doi:10.1186/1471-2334-11-198

Cite this article as: Sow et al:: The contribution of water contact behavior to the high Schistosoma mansoni Infection rates observed in the Senegal River Basin. BMC Infectious Diseases 2011 11:198.

\section{Submit your next manuscript to BioMed Central and take full advantage of:}

- Convenient online submission

- Thorough peer review

- No space constraints or color figure charges

- Immediate publication on acceptance

- Inclusion in PubMed, CAS, Scopus and Google Scholar

- Research which is freely available for redistribution

Submit your manuscript at www.biomedcentral.com/submit
C Biomed Central 